\title{
Corrigendum
}

Cite this article: Seiler A et al. (2021). Death in delirious palliative-care patients occurs irrespective of age: A prospective, observational cohort study of 229 delirious palliative-care patients - CORRIGENDUM. Palliative and Supportive Care 19, 393. https:// doi.org/10.1017/S1478951521000560

Key words:

Delirium; Palliative-care patients; Precipitating factors; Predisposing factors

\section{Death in delirious palliative-care patients occurs irrespective of age: A prospective, observational cohort study of 229 delirious palliative-care patients - CORRIGENDUM}

Annina Seiler, PH.D., David Blum, M.D., PH.D., Caroline Hertler, M.D.,

Markus Schettle, M.D., Carl Moritz Zipser, M.D., Leonie Bode, M.D., Samuel Gehrke, M.D., Jutta Ernst, PH.D., Maria Schubert, PH.D., Roland von Känel, M.D. and Soenke Boettger, M.D.

https://doi.org/10.1017/S1478951520000887, published by Cambridge University Press, 15 September 2020

In the original publication of this article (Seiler et al., 2020), the word "hypertonia" was mistakenly used in six instances where "hypertension" was meant. The locations of these instances are as follows:

- In the Results section of the abstract.

- In the first paragraph under the subheading "Determination of predisposing and precipitating factors" in the Results section.

- In the first paragraph under the subheading "Multiple regressions analysis for predisposing and precipitating factors for delirium" in the Results section.

- In Table 3.

- At the end of the first paragraph of the Discussion section.

- In the second sentence of the fourth paragraph of the Discussion section.

The abstract of the original article has been updated. The authors apologize for this error.

\section{Reference}

Seiler A, Blum D, Hertler C, et al. (2020) Death in delirious palliative-care patients occurs irrespective of age: A prospective, observational cohort study of 229 delirious palliative-care patients. Palliative and Supportive Care. https://doi.org/10.1017/S1478951520000887 